\title{
Arbeitsgruppe* Kritik der bürgerlichen Rechtsgeschichte
}

\section{SELBSTVERSTANDNIS}

"Sie zeigt, unter welchen politischen und sozialen Bedingungen sich die Rechtsnormen bilden und wie diese selbst wieder auf den Geschichtsverlauf zurückwirken, wie die Geschichte oft nichts anderes ist als die Verwirklichung des Rechts; die meisten großen Geschichts- sind zugleich Rechtstatsachen. Sie lehrt, wie Macht durch Recht gebändigt wird und das Recht selbst eine Geistesmacht ist, der sich niemand ungestraft widersetzen kann. Sie strebt nach Erkenntnis der im Einzel-wie im Völkerleben wirkenden Rechtsidee, deren Gang durch die Geschichte sie ebenso enthüllt wie die wechselseitige Bedingtheit von Persönlichkeit und Gemeinschaft ....

Aus: Mitteis-Lieberich, Deutsche Rechtsgeschichte, r 2. Aufl. München 1972, S. x, 2.

"Die Rechtsgeschichte ist, wie jede Geschichtsschreibung, idiographische Wissenschaft, d.h. sie hat es zu tun mit individuellen Vorgängen und Zuständen in der geschichtlichen Welt. Solche Individualität kommt aber nicht den Institutionen, Begriffen und Systemen als solchen zu, sondern den äußeren Akten der Rechtssetzung und Rechtsanwendung und den ihnen zugrundeliegenden Akten des menschlichen Bewußtseins und Denkens; allein in der unaufhörlichen Wechselwirkung dieser Akte schreitet die Geschichte des Rechts fort...

Vermöge der für Europa kennzeichnenden Herrschaft des methodischen Bewußtseins über das öffentliche Handeln (ist) auch die Rechtsgeschichte wesentlich eine Geschichte der Durchsetzung von Ideen in der Wirklichkeit von Staat und Gesellschaft gewesen... Doch haben sich diese Ideen in der geschichtlichen Wirklichkeit nicht immer rein ausgedrückt und ohne Verzögerungen und Widerstände durchgesetzt. ... Diese Verzögerungen erklären sich aus dem Reibungswiderstand des Gedankens am zäheren Stoff der äußeren Gegebenheiten, der die gesellschaftlichen Auswirkungen der gedanklichen Neueinsätze so oft aufhält, abflacht oder auch vorzeitig verebben läßt.«

Aus: Franz Wieacker, Privatrechtsgeschichte der Neuzeit, 2. Aufl. 1967, S. 17, 21

\section{A. Geschichte als Verwirklichung der Rechtsidee}

Den hier dokumentierten Reflexionen zweier bedeutender Repräsentanten des Fachs Rechtsgeschichte über den wissenschaftstheoretischen Status der Rechtsgeschichte und die treibenden Mechanismen historischer Prozeßverläufe ist gemeinsam die grundlegend idealistische Position: Rechtsgeschichte ist Ideengeschichte. ${ }^{1}$ Unterschiede bestehen insoweit, als der Romanist Wieacker die Individualität des Bewußtseins und Denkens betont und damit das Individuum

\footnotetext{
" Mitglieder der Arbeitsgruppe sind: Thomas Blanke, Gerhard Böhme, Thomas Huth, Ulrich Mückenberger, Eberhard Stamm, Roderıch Wahsner, Hans Wrobel; widhtige Anregungen und Kritik verdanken wir Hans Erich Troje und Christoph U. Schmindk.

1 Gängıg ist auch die Kennzeıchnung der Rechtsgeschıchte als Kulturgeschichte oder als Teil der Kulturgeschichte; vgl. dazu u. a. Helmut Coing, Epochen der Rechtsgeschichte in Deutschland, 2. Aufl. 1971, S. 2 f.
} 
ins Zentrum der geschichtlichen Entwicklung rückt, während bei den Germanisten Mitteis-Lieberich die im "Einzel- wie im Völkerleben « wirkende Rechtsidee einen Zug von Kollektivität aufweist.

Idealistische Geschichtsauffassungen lassen sich durchgängig als Ausgangspunkt der bürgerlichen Rechtsgeschichte nachweisen.. ${ }^{2}$ Die Differenzierungen reichen vom subjektiven Idealismus (Wieacker) über mystifizierende Volksgeistkonzeptionen (Schwerin-Thieme) ) $^{3}$ bis zu theologischen Positionen, die in der Rechtsidee das Wirken Gottes in der Geschichte erkennen (Erik Wolf) ${ }^{4}$. Wie verschieden auch immer die metaphysischen Begründungen für die Entwicklung des Rechts lauten, auf der Grundlage des gemeinsamen idealistischen Ansatzes kann gesellschaftliche Realität nur als im Gegensatz zur Rechtsidee befindlich begriffen werden; die unauflösliche Antinomie von gesellschaftlichem Sein und idealem Sollen bildet ein Grundmuster der rechtshistorischen Literatur. In diesem antinomischen Verhältnis wird das Sollen (die Rechtsidee, das Recht) zum bestimmenden Moment und damit zum Movens der Geschichte. So ist für Wieacker Rechtsgeschichte wesentlich Geschichte der "Durchsetzung von Ideen in der Wirklichkeit von Staat und Gesellschaft « und ihre Epochen sind jeweils durch »methodische Neueinsätze des europäischen Denkens hervorgerufen «, ${ }^{5}$ für Mitteis-Lieberich »Geschichte oft nichts anderes... als die Verwirklichung des Rechts", »Recht nicht abhängige Funktion, sondern Norm und Richtmaß der Wirtschaft « ${ }^{\mathbf{6}}$.

Zwar enthalten beide Texte Formulierungen, die eine Wechselwirkung von Recht und "Wirklichkeit « konstatieren. So erkennt Wieacker im Vorwort zu seiner Privatrechtsgeschichte (S. 8 f.) als möglichen »zeitgemäßen « (sic!) Einwand gegen seine Darstellung, »daß sie die politische und soziale Realität nur zu Worte kommen läßt, wo sie vom rechtswissenschaftlichen Bewußtsein wahrgenommen und integriert worden ist «, und rechtfertigt dies mit der Notwendigkeit, daß »der Gegenstand einer Rechtsgeschichte nur die Objektivationen des sozialen Lebens gerade in Rechtsanschauungen sein können «. Damit wird nicht nur gesellschaftliche Realität verkürzt auf das »soziale Leben«, soweit es sich in Rechtsnormen ausdrückt; der ausdrückliche Verzicht auf eine eigenständige Analyse historischer Gesellschaftsformationen hat darüber hinaus zur Folge, daß weder der Mechanismus der Transformation sozialer Verhältnisse in Rechtsverhältnisse noch die Entsprechungen bzw. Divergenzen zwischen den Formen der wirklichen Lebensverhältnisse und ihren juristischen Ausdrücken begriffen und dargestellt werden kann. Die gleichen Einwände gelten hinsichtlich der Konzeption von Ivitteis-Lieberich, deren Rechtsgeschichte angeblich zeigt, »unter welchen politi-

2 Dies gilt jedenfalls für die bislang herrschende Rıchtung der Rechtsgeschichte in der Bundesrepublik; ob sıch in den vereinzelten Aussagen einiger Rechtshıstoriker über eıne zu verändernde wissenschaftstheoretische Standortbestimmung der Rechtsgeschichte bereits ein tendenzieller Wandlungsprozeß und nıcht bloß ene freibleibende modernıstısche Programmatik ankündig erscheint fraglich (vgl. hicrzu Anm. 21).

3 Grundzüge der deutschen Rechtsgeschichte, 1950, S. 2. Anklänge an die Volksgeistkonzeption lassen sich auch bes den Germanisten Hermann Conrad, Deutsche Rechtsgeschichte, Band I, 2. Aufl. $x_{962}$, S. XVII f. ("Darstellung der geschichtlichen Entwidklung von Rechtseinrichtungen und Rechtsgedanken im deutschen Volke... Rechtsformen und Rechtseinrichtungen entwidkeln sıch im lebendigen Strom einer Gemeinschaft und sind mithin der geistıge Ausdrudk der Kultur. Diese Erkenntnıs macht die Rechtsgeschichte weitgehend zur Kulturgeschichte «) und be1 Mitters-Liebertch, Deutsche Rechtsgeschichte, 12. Aufl. 1971, S. 2 f. (vgl. dazu Wabsner, in diesem Heft, S. 172 ff.) nachweisen.

${ }^{4}$ Große Rechtsdenker der deutschen Geistesgeschichte, 4. Aufl. 1963 , S. III f. Für Walter Schönfeld, Grundlegung der Rechtswissenschaft, r95I, S. I, 3, 4 und pass. wird Rechtsgeschichte vollends zur christlichen Heilslehre.

5 Privatrechisgeschichte der Neuzeıt, a. a. O., S. 20.

B Deutsche Rechtsgeschichte, a. a. O., S. 20. 
schen und sozialen Bedingungen sich die Rechtsnormen bilden «. Der Reflexionsfortschritt gegenüber der 1948 von Heinrich Mitteis herausgegebenen Schrift "Vom Lebenswert der Rechtsgeschichte", in der dieser entsprechend seinem Credo "Nicht die >normative Kraft des Faktischen< entscheidet, sondern die faktische Kraft der Norm « ${ }^{7}$ das Recht zum Geburtshelfer, wenn nicht gar Erzeuger säntlicher vom Autor gutgeheißener sozialer Verhältnisse stilisiert hat ${ }^{8}$, reduziert sich auf die sicherlich zeitgemäßere abstrakte Versicherung, daß die staatliche Ordnung "auf wirtschaftlichen und sozialen Grundlagen « beruht und Wirtschaft und Recht in "steter Wechselbeziehung « stehen. ${ }^{*}$

In diesen Konzeptionen von Rechtsgeschichte erscheint die soziale Realität bestenfalls als illustrativ herangezogene Umwelt, als die Kulisse der Bühne, auf der die Rechtsidee ihre geschichtlichen Taten vollbringt. Wirtschaft und Gesellschaft bilden lediglich die notwendigen »äußeren Faktoren ${ }^{10}$, die »ökonomische und soziale Umwelt«, einen Teil der "gesamten kulturellen Umwelt «"11, in die das Recht eingebettet ist. Dabei stellt sich diese "Umwelt « dem historischen Subjekt Recht notwendig als Hemmnis entgegen: "Doch haben sich diese Ideen in der geschichtlichen Wirklichkeit nicht inmer rein ausgedrückt und ohne Verzögerungen und Widerstände durchgesetzt «, was »am Reibungswiderstand des Gedankens am zäheren Stoff der äußeren Gegebenheiten « liegt (Wicacker).

Das so verstandene Verhältnis von Recht und Wirklichkeit legt das Fundament für die hohepriesterliche Funktion des Juristenstandes: Die Rechtsdenker übernehmen die Aufgabe der Vermittlung der mit unterschiedlichen Inhalten angereicherten Rechtsidee mit der Rechts- und wirklichen Wirklichkeit, der elitäre Stand hat sich ein entsprechendes Bewußtsein und historische Legitimation verschafft. Schaut man genauer zu, so sind es jetzt allein die Juristen, die als Propheten der Rechtsidee Geschichte machen: Das transzendentale Geschichtssubjekt hat sein materielles Substrat gefunden. Diese Konzeption, die im Zentrum von Wieackers Darstellung der Privatrechtsgeschichte der Neuzeit steht, bringt Erik Wolf auf den Begriff: "Sie (die großen Rechtsdenker) sind Zeugen von Gottes Wirken in der Welt, das heißt, in ihrem Wesen und Werk erfahren wir etwas vom Sinn der Geschichte und damit vom Sinn unseres Lebens «. "Sie treten vor unser geistiges Auge als ein langsam sich bildender, aus dem Dunkel der Vergangenheit gelassen emporsteigender und in das Dunkel der verborgenen Zukunft hinüberleuchtender Zug von Fackelträgern «13 des Rechts. Im Augenblick leuchtet der Zug der utopiearmen bürgerlichen Rechtsgelehrten nicht in historisch, qualitativ neue Epochen, sondern in die geographische »Umwelt « Europa: "Ohne eine Neubegründung des Rechtsglaubens wird es auch keine $\mathrm{Zu}$ kunft des europäischen Privatrechts geben... Die großen Zeiten der Privatrechtsgeschichte waren immer Epochen, in denen das Rechtsbild des Juristen in ausdrücklichem oder unbewußtem Einklang mit dem Gesellschaftsbild ihrer Zeit stand ... Die Privatrechtswissenschaft wird sich durch Richter und Rechtsgelehr-

7 Rechtsgeschichte und Machtgeschichte, in: ders., Die Rechtsidee in der Geschichte, S. 280.

8 Vom Lebenswert der Rechtsgeschichte, S. 6I: Das Recht ist moft der Pionier einer gerechten

Wirtschafts- und Sozıalordnung gewesen ", und S. 62: Das Recht hat sich "oft genug wirtschaftlichen Mißständen entgegengestellt «.

9 Mittets-Liebertch, Deutsche Rechtsgeschichte, S. 2.

I0 Dgl., A. a. O.; vgl. auch Wesenberg-Wesener. Neuere deutsche Privatrechtsgeschichte im Rahmen der europäischen Rechtsentwicklung, 2. Aufl., I969, S. 7: „Privatrechtsgeschıchte hat die Entwicklung privatrechtlicher Dogmen und privatrechtlicher Institutionen vorzutragen und die geıstıgen und sozıalen Hinteroründe (!) dieser Erscheınungen zu erklären.*

11 Mitteis, Vom Lebenswert der Rechtsgeschichte, S. 39, $45 \mathrm{f}$.

12 Erik Wolf, Große Rechtsdenker, 4. Aufl. 1963, S. III.

13 A. a. O., S. IV. 
te wieder erheben, die sich dieser Vorbedingungen vergegenwärtigen und denen ihre Zeit das Gehör nicht versagt. «14

Haben sich somit als Träger der geschichtsmächtigen Rechtsidee die großen Rechtsdenker (einschließlich der Veranstalter des olympischen Fackelzuges, der Rechtshistoriker selbst) entpuppt, so bleibt angesichts der jeglicher historischgesellschaftlicher Bestimmtheit entkleideten Rechtslarve, die sie durch die Geschichte tragen, zu fragen, welcher Inhalt der Rechtsidee dann überhaupt noch zukommt. "Der zentrale Beziehungspunkt der Rechtsgeschichte ist das Recht; sie wertet alle historischen Vorgänge, indem sie sie auf den Rechtswert bezieht, nach spezifisch rechtlichen Kategorien ${ }^{15}$. Das Recht wird zum moralischen Maßstab gesellschaftlicher Verhältnisse, der Maßstab selbst gewonnen aus der einzigen sozialen Funktion, die die dem Rechtsstaatsmodell verhafteten Rechtshistoriker als geschichtlich allgemeine zu erkennen glauben: Der Antinomie von Sein und Sollen entspricht die von Recht und rechtlich gebändigter Macht (Herrschaft) einerseits und blinder, ungebändigter Macht (Chaos) andererseits; Aufgabe des Rechts (einschließlich des Privatrechts!) ist es, Macht zu begrenzen. Indem Recht als die »lebensbedingende Ordnung der Gemeinschaft «18 der nackten Macht entgegentritt und sie fesselt, verhindert es Chaos und Anarchie und schließt die voneinander unabhängigen, ihre egoistischen Interessen gewaltsam verfolgenden Individuen erst zur bürgerlichen Gesellschaft zusammen. Seitdem "läßt sich beweisen, daß auch in den gespanntesten Machtlagen die Konfliktsentscheidungen regelmäßig vom Recht diktiert waren... Die Macht selbst beruht im Grunde nur auf der Chance, rechtliche Vorteile ausnützen zu können. Auch der Mächtigste durfte sich auf die Dauer nicht ungestraft über das Recht hinwegsetzen. «17

Die Antinomie von Recht und Macht wird in gleicher Weise "gelöst « wie die von Sein und Sollen: durch definitorische Negation der Antinomie. Das Sollen bezwingt das Sein, das Recht die Macht. Wer sich über das Recht hinwegsetzt, wird gestraft. Im gesellschaftlichen Normalfall werden Recht und Macht identisch, zugleich Macht als »die Chance, rechtliche Vorteile ausnützen zu können «, durch die heiligen Weihen der Rechtsidee legitimiert. Als Inhalt der Rechtsidee offenbart sich die gesellschaftliche Funktion des Rechts: Die Legitimation von Herrschaft. Rechtsgeschichte wird zur Legitimationswissenschaft.

Dieses Dilemma der bürgerlichen Rechtsgeschichte spiegelt sich noch in den politischen Biographien bedeutender zeitgenössischer Rechtshistoriker. Es erklärt die Leichtigkeit, mit der teilweise die gleichen Personen, die im Faschismus die Aufgabe wahrnahmen, den Nationalsozialisten historische Legitimität zu verschaffen, mit Hilfe der neu aufgefrischten Rechtsidee zur Legitimation neuerer $\mathrm{Zu}$ stände und zur Verurteilung des »Dritten Reiches « als »Gegenteil « des Staates ${ }^{18}$ bzw. als "Gewaltherrschaft « übergehen konnten. Auch in der Uberwindung des Faschismus ${ }^{10}$ zeigt - nachträglich - die Rechtsgeschichte, »wie schließlich trotz aller Rückschläge immer wieder der Geist die Materie gebändigt hat. Sie hilft uns, eine Zeit zu ertragen, die uns die Schwere und Bedrohtheit unserer Existenz täglich und stündlich zum Bewußtsein bringt.«20 Die kompromittierte bürger-

\footnotetext{
14 Wieacker, Privatrechtsgeschichte der Neuzeit, S. 620, 625.

15 Mittels, Vom Lebenswert der Rechtsgeschichte, S. 59.

18 Mitteis-Lieberich, Deutsche Rechtsgeschichte, S. I.

17 Mitteis, Vom Lebenswert der Rechtsgeschichte, S. 64

18 Walter Schönfeld, Grundlegung der Rechtswissenschat, 195 I, Vorwort und S. 3 u. 4.

19 Vgl. dazu Wahsner, in diesem Heft, S. 172 ff.

$20 \mathrm{Vgl}$. Mitteis, Vom Lebenswert der Rechtsgeschichte, S. I29 f.
} 
liche Rechtsgeschichte ist nicht mehr nur Legitimationswissenschaft. Sie wird zur Heils- und Erlösungslehre für diejenigen, die auf die Worte der großen Rechtsdenker lauschen und den Rückzug aus der schlechten historischen, gesellschaftlichen und politischen Wirklichkeit ins geheiligte Internum der Idee (gemeint sind die Institutsbibliotheken) angetreten haben. ${ }^{21}$

\section{B. Wissenschaftssoziologische Aspekte}

Die Formen der Produktion und Reproduktion des Wissenschaftsbetriebes der bürgerlichen Rechtsgeschichte lassen sich nur im allgemeineren Rahmen der Analyse ihres institutionellen Kontextes, der (gegenüber Studenten und Assistenten) feudalen Struktur der Ordinarienuniversität zureichend verstehen. Diese Analyse soll hier nicht wiederholt werden. Vielmehr geht es darum, die Organisation des Forschungs- und Lehrbetriebes bürgerlicher Rechtsgeschichte in ihrer Besonderheit gegenüber anderen Wissenschaftszweigen darzustellen. Für diese Fragestellung kommt zunächst dem Gegenstandsbereich, den sich dieser Zweig der »Rechtswissenschaft « erschlossen hat, primäre Bedeutung zu.

Die gegenwärtige Praxis der römischrechtlichen (sog. romanistischen) Forschung - auf die wir zunächst eingehen wollen - geht zurück auf eine in den achtziger Jahren des 19. Jahrhunderts erfolgte thematische Reduktion: Die Interpolationenforschung, die sich ausschließlich mit der Herausarbeitung der verschiedenen Entwicklungsstufen römischer Rechtsquellen, angefangen von den »klassischen « römischen Juristendicta über die Bearbeitung der Texte unter Diokletian, Konstantin bis hin zu Justinian beschäftigt. In den Unterrichtsbetrieb reicht dieser Forschungszweig durch die Veranstaltung "Digestenexegese « hinein.

Angesichts der wenigen originalen Zeugnisse aus der Zeit der klassisch-römischen Jurisprudenz und der von fundierten Kenntnissen der tatsächlichen ökonomischsozialen Entwicklungen ungetrübten, rein spekulativ-logizistischen Interpretationsweise der Romanisten blieb die versuchte Rekonstruktion ursprünglicherer

21 In neuerer Zeit scheint sich das Bewußtsein von der sklerotischen Erstarrung und wissenschaft. lichen Isolierung der Rechtsgeschichte auch bei einıgen Rechtsgeschıchtlern selbst anzukündigen. So können für Dieter Simon (Artikel >Rechtsgeschıchter im Handlexikon der Rechtswissenschaft, I972 S. 314 [3I5]) die Lesstungen der Rechtsgeschichte, sowett sie Dogmengeschichte oder Geschichte des Denkens der Jurısten seı, »weder das überwiegende noch gar das einzıge Ziel rechtshistorischer Forschung sein... Soll Rechtsgeschichte aber wesentlich Sozıalgeschichte seın, dann hat sie... die historische Gesellschaft in ihrer Totalität zum Bezugspunkt«. Nach Karl Kroesdhell (Deutsche Rechtsgeschichte Bd. I, 1972, rororo Studium Bd. 780, S. 3) muß ein reformiertes rechtswissenschafliches Studium »... vor allem begreiflich machen, daß und in weIcher Weise Rechtswissenschaft nur als Teil der Sozialwissenschaften den theoretischen und praktıschen Anforderungen der wissenschaftichen Zivilisatıon (?) genügen kann« und selbst Franz Wieacker, der in dem eingangs aufgeführten Zitat Rechtsgeschidite noch als »Ideographische Wissenschaft « bezeıchnet, verzıchtet I 971 auf diese Kennzeıchnung (Artikel Rechtsgeshichte، in: Fischer Lexikon Recht, Neuausgabe 1971, S. I37); er geht nunmehr davon aus, daß Rechtsgeschichte wein selbständiges Interesse als vergangene Wirklichkeit menschlicher Gesellschaften « habe und konstatiert, daß sie "von hier (?) aus . . . ein Ausschnitt der Sozialgeschichte "seı. Indes: Drei Schwalben machen noch keınen Frühling; das oben skizzierte Elend der Rechtsgesduchte entspridht immer noch dem herrschenden Selbstverständnis - und ist damit meilenweit von dem (in aller Bescheıdenheıt) andernorts bereıts zum selbstverständlichen Gerede herabgekommenen Topos der „Einbeziehung « der Sozıalwissenschaften entfernt. Inwieweit die hier aufgeführten "dissentierenden * Autoren aus ihrer Einsicht Konsequenzen für Fragestellung und Methodik ihrer Forschung ziehen werden, bleibt abzuwarten. Angesidits der nirgendwo explizierten Präzısierung der modernistıschen Kategorıen "Totalität«, »Sozialwissenschaften*, "Sozlalgeschıchte $a$ etc. für das hier interessierende Verhältnis von Recht und Geschichte erscheint es ratsam, die Wartefrist durch den hier vorgelegten Diskussionsbeitrag ein wenig unterhaltsamer zu gestalten. 
Textstufen aus den nachklassischen bzw. byzantinischen Erläuterungen und Veränderungen der Rechtsgrundsätze notwendig der Beliebigkeit der je privaten Meinung der Rechtshistoriker darüber, was der Klassiker hierzu und dazu hätte sagen können, dürfen oder müssen, überlassen. Die von diesem Wissenschaftsbetrieb sich praktisch ausschließlich gestellten Probleme könnte man in etwa vergleichen mit der Aufgabe, aus der 17. Auflage des Palandt oder des Reichsgerichtsrätekommentars zum BGB bei nur bruchstückhafter Kenntnis bzw. Überlieferung früherer Auflagen und originaler Texte einzelner Mitautoren herauszudestillieren, welcher Teil von wem stammt und welches die ursprüngliche Fassung der einzelnen dogmatischen Normen und des Gesamtsystems gewesen sei.

Können somit für uns im Rahmen einer Bestimmung des Status der Romanistik die inhaltlichen Resultate dieser Arbeit auf Grund ihrer praktischen Bedeutungslosigkeit für eine sozialwissenschaftliche Analyse der ökonomischen und politischen Bedingungen sowie der ideologischen Reflexe des Untergangs der römischen Sklavenhaltergesellschaft als nebensächlich gelten, so interessiert um so mehr die soziale Funktion der Restriktion des wissenschaftlichen Gegenstandsbereichs auf einen eng begrenzten Bereich spätrömischer Juristentexte und deren ständig wiederholte Exegese.

Als vorläufige Erklärungsmuster bieten sich an: Das Ende des 19. Jahrhunderts wird in seiner sozialen Entwicklung gekennzeichnet durch den gemeinsamen Abwehrkampf von Adel, Monarchie und Bürgertum gegen die sich formierende Arbeiterklasse. OKkonomisch war die Bourgeoisie längst als herrschende Klasse etabliert, die Produktion eines ungestörten Kapitalverwertungsprozesses bedurfte der Herstellung eines im nationalen Rahmen organisierten Marktes, der großen Kodifikation des Rechts als verbindlicher und einheitlicher Regulierung der kapitalistischen Verkehrsformen.

In diesem Prozeß, in dem die Summe aus den historischen, den römischen wie germanischen und gemeinrechtlichen Rechtsregeln, soweit sie als Modelle der einfachen Warenproduktion sich auch der kapitalistischen Zirkulation zwanglos fügten, gezogen werden sollte, war das Ende einer gesellschaftlich-praktischen Relevanz römischrechtlichen Quellenstudiums absehbar: Von der inhaltlichen Erschließung und Aufbereitung ihrer Quellen für eine folgenreiche dogmatische Verarbeitung oder für eine unmittelbare forensische Verwertung degeneriert die Romanistik zur abstrakten Schulung in zivilistischer Dogmatik.

Der historische Wandlungsprozeß vom klassisch-römischen zum justinianischen Recht, von der Struktur der Einzelfallbegutachtung und -entscheidung im Entstehungs- und Uberlieferungsrahmen der beiden konkurrierenden topischen Ordnungsgefüge (sog. "Ediktsystem " einerseits, "Sabinussystem « andererseits)22 über das diokletianische Reskript zum Stil der konstantinischen, theodosianischen, schließlich justinianischen Gesetzgebung ${ }^{23}$ wird als Verfallserscheinung der ursprünglich klaren, knappen und ebenso unbegründeten wie autoritären Entscheidung der klassisch-römischen Juristen interpretiert; die Romanistik, mit "antibyzantinischem Affekt", hat den Byzantinismus, deren Gesetzgeber und Kommentatoren viel differenzierter auf »wirkliche Lebensverhältnisse«, auf so-

22 Das Edikt des Praetors ist eine Aufzählung zulässıger Klagen und Rechtsbehelfe in bestimmter, historisch gewachsener Form. Die Ediktsordnung bestimmte den Umriß und die Struktur nicht nur der Ediktskommentare, sondern auch der großen justinianischen Sammlungen (Digesten und Codex Iustinianus). Andrerseits wurde den klassischen Kommentaren des Zivilrechts auch das Hauptwerk des Sabinus wie ein Gesetzestext zugrundegelegt; vgl. DuldkeitSchwarz, Römische Rechtsgeschichte, 5. Aufl. München r970, S. 240.

23 Uber die Formen der kaiserlichen Gesetzgebung (Konstıtutionen) vgl. Leopold Wenger, Die Quellen des römıschen Rechts, Wien 1953 , S. $424 \mathrm{ff}$. 
ziale Voraussetzungen und Folgen der Entscheidungen reflektierten ${ }^{24}$, auf der Basis des idealisierten preußischen Juristenpuritanismus als "Aufweichung " rechtsstaatlich-dogmatischer Brillianz charakterisiert. Im wortkargen römischen Juristen, der bei Gerhard Beseler in seinem Sprachpurismus fast schon zur Karikatur verzerrt, bei Fritz Pringsheim zur Inkarnation römischer Aequitas vergeistigt worden ist, mystifiziert sich die Projektion des preußischen Rechts- und Staatsdieners.

Die inhaltliche » Richtigkeit « der Entscheidung erscheint verbürgt in der Attitüde des Standes. Diesen Juristentypus auf nationaler Ebene einheitlich in Sprachund Verhaltensmuster zu sozialisieren, das war die neue Aufgabe, die sich die römische Rechtsgeschichte erschloß. Kein Zufall, daß die venia für Bürgerliches Privatrecht ehernes Pendant dieses Faches wurde, daß der geschulte Romanist lange Zeit eo ipso als »guter Jurist « galt und daß an den berühmten Úbungsfallsammlungen renommierter Romanisten wie z. B. Otto Lenels ${ }^{25}$ ganze Generationen von Juristen geschult und geprüft wurden.

Die Entwicklung der Romanistik im 20. Jahrhundert ist gekennzeichnet von dem Widerspruch, in den das Glasperlenspiel der Interpolationenkritik und Textstufenforschung ${ }^{26}$ und die Artistik reiner Digestendogmatik zur zivilrechtlichen Dogmatik der hochkapitalistischen Gesellschaft trat. In dem Maß, indem sich dieses politisierte und schließlich gänzlich für Zwecke wirtschaftlicher Steuerung mobilisiert wurde (so im Bereich des Arbeits-, Eigentums- und Wettbewerbsrechts in der Weimarer Zeit ${ }^{27}$, im Bereich des Boden-, Familien- und Erbrechts im Nationalsozialismus), mußte die Ausbildung in den Strukturen einer bloß "ästhetischen " reinen Dogmatik und formalen Systematik bei Aufrechterhaltung einer antipopulistischen elitären Standesideologie aus der Zeit der konstitutionellen Monarchie tendenziell zu einem Hindernis für die ideologische Anpassung an die reale gesellschaftliche Entwicklung werden.

So ist der weitere Gang der Romanistik ein fortschreitender Rückzug von der gesellschaftlichen und politischen Realität in das Arkanum der Institutsbibliotheken, die mit ihren immer perfekteren - freilich stets mechanischen - Hilfsmitteln der Materialerfassung ${ }^{28}$ dem Kultus vollständiger Quellenverwertung und ahistorischer "Werktreue ebenso Vorschub leisten wie einem letztlich gedankenlosen, handwerklich erlernbaren Arbeitsstil. In der Weimarer Republik und im

24 Hans Erıch Troje, Europa und griechisches Recht, Frankfurt I971, S. 25 und passım.

25 Otto Lenel, Praktikum des Bürgerlichen Rechts. Praktische Rechtsfragen zum Gebrauch bei Übungen und Vorlesungen, 9. Aufl. Leıpzıg I922; zu nennen wären hier ferner die berühmten "Zivilrechtsfälle ohne Entscheıdungen« von Rudolph yon Iherıng, 13. Aufl., Jena 192s (bearbeitet yon Paul Oertmann) sowı Theodor Kipp und Martin Wolff, Zivilrechtsfälle, Berlin I924. Es bliebe noch zu prüfen, in welchem Umfange sich dieses letzrlich romanistische Fallmaterial im heutigen Ausbildungs- und Repetitoriumsschriftum wiederfindet.

26 Ebenso endrucksvoll wie gespenstısch ist dieses Spiel auf die Spitze getrieben im Werke von Franz Wieacker, Textstufen klassischer Jurısten, Göttıngen 1960, welches sich der intersubjektiven Nachprüfung schon der engsten Fachkollegenschaft weitgehend entzieht.

27 Vgl. hierzu die Studie von Joachım Perels, Kapıtalismus und politısche Demokratie, Privatrechtssystem und Gesellschaftstruktur in der Weımarer Republik, Ffm 1973.

28 Das Vocabularıum Iurisprudentıae Romanae, nach jahrzehntelanger Arbeit bald abgeschlossen, gibt für jedes Wort sämtliche Fundstellen aus den Digesten und den außerhalb davon überlieferten Schriften der klassischen Jurısten. Entsprechende Wortındices existieren zum Codex Iustınıanus, zum Sprachgebrauch nur der justınıanıschen Konstıtutıonen sowie zu fast sämtlichen Texten der vorjustınianıschen Gesetzessammlungen (z. B. Codex Theodosıanus) und Einzelschriften (z. B. Gasus-Institutionen). Der gleichfalls noch nicht abgeschlossene Index Intexpolationum yerweist für jedes Digestenfragment auf die in der neueren Literatur vertretenen Ansichten zur Echtheit des Textes. - Eine Einführung in die romanistischen Arbeitstechniken und Arbeitshilfsmittel vermittelt Uwe Wesel, Die Hausarbeit in der Digestenexegese. Eine Einführung für Studenten und Doktoranden, München r 966 , hier zu den erwähnten Indices S. $25 \mathrm{f}$. 
Faschismus überwiegend weder engagiert noch kompromittiert ${ }^{29}$ erlebte sie nach dem Zweiten Weltkrieg in der neoliberalen Phase der Bundesrepublik eine kurze Auferstehung; die romanistischen Seminare, die mit kleinen und kleinsten langjährig zusammenbleibenden Schülerkreisen Digestenkunde zelebrierten, hielten sich für die eigentlichen Bewahrer jener innerelitären Hochkultur, der sich die Weltgeltung deutscher Jurisprudenz des 19 . Jahrhunderts verdankt. ${ }^{30}$

Dieser kurze Abriß über Gegenstand, Methode und gesellschaftliche Funktion der Romanistik macht erklärlich, wieso sich in dieser Sparte der Rechtswissenschaft die feudale Form der Produktion wissenschaftlicher Arbeit so besonders rigide ausgeprägt und im Kern bis heute ungebrochen erhalten hat: Der dogmatischen Kanonisierung des Quellenmaterials entspricht die Herrschaft bestimmter Interpretationsschulen, die sich angesichts der durchgängigen methodologischen Borniertheit auf das Charisma einiger weniger Gelehrter reduziert. Ursprünglich angeführt von den Begründern dieser Interpolationstechnologie ${ }^{31}$ erbte sich die deutsche Romanistik als eine Art wissenschaftlicher Geheimgesellschaft des humanistisch gebildeten Gelehrtenpatriziats in wenigen übersichtlichen und untereinander verflochtenen Dynastien fort. Von der Basis familiärer Verflechtung mit der Großbourgeoisie gelingt einigen wenigen Vertretern dieses Gelehrtentyps der Vorstoß in Führungsgruppen des Bildungsbürgertums, die übrigen verfallen dem mittleren Bürger- bzw. Kleinbürgertum, dem sie zumeist selbst entstammen. Das ihnen gemeinsame Charakteristikum fehlenden historischen Bewußtseins findet seinen Niederschlag in der ahistorischen Forschungspraxis ebenso wie in der Flucht vor aktuellen politischen und gesellschaftlichen Ereignissen. Gemeinsam kennzeichnet sie aber auch der Mechanismus der Kompensation dieser Angst vor der Geschichtlichkeit ihrer eigenen Existenz. (d. h. Klassenlage) und der idealisierten Privatrechtsgesellschaft: neurotische Isolation, Rückzug auf hörige Schülerkreise, Ausschluß öffentlich-fachübergreifender wissenschaftlicher Diskussion ${ }^{32}$, Flucht in andere unzugängliche oder jedenfalls nicht wissenschaftlich kontrollierbare Detailgebiete, Selbstbestätigung durch preußische Arbeitsdisziplin, Intaktheit, Fetischismus; kein Wort der Digesten, kein "und «, "auch « und »aber « des Codex Justinianus sowie der nichtjustinianischen Quellen, das nicht in Zettelkästen geführt oder in aufwendig ausgedruckten Wortindizes nach Fundstellen nachgewiesen wäre. ${ }^{33}$

${ }^{2 \theta}$ Mit ganz gerıngen Ausnahmen wie z. B. Kantorowıcz, einem der Begründer der Freırechtsschule, die ihrerseits noch den Traditıonszusammenhang mit der Romanıstik ınsofern verrät, als sie - gespeist aus der kleunbürgerlichen Reaktıon auf die imperıalistısche Konzentration des Kapitals - den dezısıonıstıschen römıschen Rıchterkönıg exhumıert. Ferner wäre hıer Franz Wieacker zu nennen, der im Nationalsozıalismus nicht abseıts stehen mochte, vgl. hierzu Anm. 22 ber Wahsner, Die Deutsche Rechtsgeschichte und der Faschismus, in diesem Heft S. 176.

30 Das "System " von Georg Friedrich Puchta (1798-1846) (System des Gemeinen Civilrechts, München 1832) sein Pandektenlehrbuch (Leipzig i 838, I2. Auflage von Schirmer, 1877), die "Pandekten « von Heinrich Dernburg und Bernhard Windscheid und ähnliche Werke der »Pandektistik « sınd Klassiker nıcht nur deutscher, sondern europäischer Jurisprudenz. Sie werden ın den einzelnen natıonalen Redhtsdogmatiken - häufig auch in Übersetzung - bıs heute ständig zıtıert.

31 Die Begründer der modernen Interpolationenforschung sind in Deutschland Friedolin Eisele (1837-1920) und Otto Gradenwitz (1860-1935), in Italien Ilario Alibrandi (I823-1894). Zwischen der deutschen und der italienischen Romanistik bestand stets ein besonders enger $\mathrm{Zu}-$ sammenhang; vgl. im einzelnen Leopold Wenger, Die Quellen des römischen Rechts, Wien I953, S. 855 ff., und, zum heutigen Stand der Textstufenforschung, Franz Wieacker, Textstufen klassischer Jurısten, Göttingen 1960, S. 9 ff.

32 Kein Witz: "Romanisten « und "Germanisten " veranstalten zwar gemeinsam den "Deutschen Rechtshistorikertag* (alle zwei Jahre, zuletzt in Nürnberg-Erlangen, häufig auch im deutschsprachıgen Auslande), tagen jedoch in getrennten Sektionen; vgl. hierzu: "Statt einer Glosse", in diesem Heft S. 210 ff.

33 Vgl. die in Anm. 28 erwähnten Indices und Hilfsmittel. 
Auch die neuerschlossenen Arbeitsgebiete organisieren sich nach dem Arbeitsstil der "klassischen « Romanistik. Die Papyrusfunde insbesondere des griechischrömischen Ägyptens haben der Schule von Ludwig Mitteis ein neues Arbeitsgebiet erschlossen. ${ }^{34}$ Die Arbeit am Wörterbuch der juristischen Papyrologie endet nicht. Die attischen Gerichtsreden geben neuen »Arbeitsstellen für griechisches Recht « (Freiburg im Breisgau) mit dem neuen Arbeitsstoff auch die Immunität gegen Konkurrenz und Nachprüfung. Auf dem Forschungsgebiet der mittelalterlichen juristischen Handschriften ist mit der relativ zufällig eroberten Teilhabe an der Verfügung über Produktionsmittel (der berühmte Nachlaß Emil Seckels fiel an Erich Genzmer) die Gelehrtenkarriere und wissenschaftliche Reputation schon fast garantiert. Gerade hier ist jede breitere intersubjektive Nachprüfung ausgeschlossen.

Die gegenwärtigen Entwicklungstendenzen der deutschen Romanistik lassen sich als die wohl letzte mögliche Fluchtbewegung beschreiben: Die Flucht vor dem eigenen Fach. Längst aus allen offiziellen Studienplänen verbannt, ist die dogmatische Kunstlehre der Digestenexegese und der pseudophilologischen Geheimkunst der Textstufenforschung der Zerstörung des preußischen Rechtsstaats selbst zum Opfer gefallen. Der Anschluß an die geschichtswissenschaftliche Altertumsforschung, die längst an der Widerlegung des bei den Romanisten fortgeschriebenen Standardwerkes von Theodor Mommsen über die römische Geschichte arbeitet, ist verloren. ${ }^{35} \mathrm{Im}$ großen "Handbuch der klassischen Altertumswissenschaft « ist die vor Jahrzehnten an Wolfgang Kunkel in Auftrag gegebene »Römische Rechtsgeschichte " nach wie vor ungeschrieben, während Max Kasers »Römisches Privatrecht « schon in die zweite Auflage gegangen und in der Kurzfassung des Beck'schen Lehrbuchs relativ weit verbreitet ist. ${ }^{36}$ Kunkels als Vorstudie zu seiner "Rechtsgeschichte « entstandenen "Studien zur Sullanischen Gerichtsreform «37 sind durch die verfassungsgeschichtlichen Untersuchungen Jochen Bleickens ${ }^{38}$ bereits weitgehend überholt. Flume, Mayer-Maly, Medicus u. a. sind vollständig zum Zivilrecht übergewechselt und betreiben ihr skurriles romanistisches Handwerk allenfalls noch als Erbauung und zur Erhaltung des Romanistenstatus. Osterreich und die Schweiz, in denen eine romanistische Grundausbildung für alle Jurastudenten noch obligatorisch ist, bieten deutschen Romanisten nur beschränkte Zuflucht. Die langen Wartelisten für Veröffentlichungen in der romanistischen Abteilung der Savigny-Zeitschrift für Rechtsgeschichte sind leergefegt. Nach Manuskripten wird gefahndet.

Die Doppelherrschaft der letzten Dynasten Kaser und Kunkel steht auf tönernen Füßen. Die römische Rechtsgeschichte der letzten hundert Jahre liegt im Sterben.

Weitgehend anders - und doch nur als die andere Seite bürgerlicher Geschichtsforschung - stellt sich das Bild der Deutschen Rechtsgeschichte (Germanistik) dar.

34 Zur juristischen Papyrologie vgl. Leopold Wenger, a. a. O., S. 78 ff.

35 Zur Auseinandersetzung heutiger Althistoriker mit Theodor Mommsen vgl. Alfred Heuß, Theodor Mommsen und das 19. Jahrhundert, Kiel 1956.

${ }^{36}$ Max Kaser, Das römische Privatrecht, 2 Bände, München 1955-1959 (inzwischen in 2. Aufl., München 1970) bildet die Grundlage des Bedkschen Kurzlehrbuches vom gleichen Verfasser, das 1972 in 7. Aufl. erschienen ist. Kasers große Darstellung des römischen Zivilprozeßrechts erschien gleichfalls im Handbuch der Altertumswissenschaft, München 1964 .

37 Wolfgang Kunkel, Untersuchungen zur Entwidklung des römischen Kriminalverfahrens in vorsullanischer Zeit, Mündhen 1962.

38 Jochen Bleıdken, Senatsgericht und Kaisergericht, Göttingen I 962. 
Die Trennung in eine germanistische und eine romanistische Richtung hat politische Gründe. Während zu Zeiten der Etablierung der Historischen Rechtsschule Germanisten und Romanisten noch vereint standen - an der Gründung der »Zeitschrift für geschichtliche Rechtswissenschaft" war neben dem Romanisten Savigny auch der Germanist Eichhorn beteiligt -, kam es zur Spaltung, als die Germanisten begannen, den Forderungen des liberalen Bürgertums die rechtliche Stütze zu liefern. In bewußter Wendung gegen den als Hort des Konservatismus angesehenen romanistischen $Z$ weig der Schule und gegen das dort gepflegte, als mit bürgerlichen Zielen unvereinbar empfundene römische Recht, machten sich die Germanisten daran, die Grundlagen der Kodifikationsfeindlichkeit der historischen Schule zu zerstören und gegenüber der Bevorzugung des Juristenrechts durch die Romanisten das »Volk « wieder in seine Rolle als »Rechtsbildner « einzusetzen. Die Germanistik war die bürgerliche Rechtswissenschaft des Vormärz. Ein führender Germanist, Georg Beseler, hat nach zeitgenössischem Zeugnis die Rechtswissenschaft auf den Weg zur Revolution geführt ${ }^{39}$; die auf den Germanistentagen von Frankfurt (I 846) und Lübeck (1 847) versammelten Germanisten »betrachteten sich als eine Art deutsches Vorparlament ${ }^{40}$.

Nach dem Scheitern der Revolution und dem alsbald sich vollziehenden Kompromiß der Bourgeoisie mit dem Adel verlor die germanistische Richtung ihre Funktion als juristische Sicherung bürgerlicher Forderungen. Insbesondere die Kodifikationsfeindlichkeit der historischen Schule Savignyscher Prägung war überwunden; die für die Bourgeoisie besonders interessanten Materien des Wechselrechts und Handelsrechts wurden reichseinheitlich - wenn auch im Wege einzelstaatlicher Gesetzgebung --geregelt. Hinzu kam ein Wandel der Einschätzung des römischen Rechts durch die Bourgeoisie. Es erwies sich, daß die Pandektenwissenschaft in ihren Grundbegriffen Privatautonomie, subjektives Recht und Eigentum mit Mitteln arbeitete, die in einem privatkapitalistischen System von fundamentaler Bedeutung waren. Während so das römische Recht zum bevorzugten Recht der Kapitalistenklasse wurde, nahm die germanistische Richtung antiliberale und kapitalismusfeindliche Züge an; diese finden sich deutlich ausgedrückt im Werk Otto von Gierkes, dessen Sozialtheorie »sich an dem veralteten Modell der vorindustriellen Gesellschaft orientiert und die Realität der Wirtschaftsgesellschaft des späten 19. Jahrhunderts nicht mehr bewältigt hat«11.

Nachdem der in der zweiten Hälfte des 19. Jahrhunderts unternommene Versuch, ein dem römischen Institutionensystem entsprechendes System der privatrechtlichen Institutionen für das deutsche bzw. germanische Recht zu erstellen ${ }^{42}$, an der Beliebigkeit der Kompositionen des Quellenmosaiks gescheitert war, zerfielen erst die Einheit, dann noch die Fronten der germanistischen Schulenbildung. Seither versucht jeder sein Glück auf eigene Faust. Dem Schatzsucher vergleichbar, der zufällig fündig wurde, erfolgt der Aufstieg zu wissenschaftlichem Renomee: Durch neue Quellenfunde und eine ausgefeilte Verwertungstechnik, die erst einiges bruchstückhaft im Rahmen von Detailuntersuchungen, dann nach und nach als kommentierte Edition den Fund der wissenschaftlichen Offentlichkeit preisgibt. Von exakter historisch-kritischer Arbeitsweise regelmä-

39 Vgl. Carl Friedrich Joseph Götting, Recht, Leben und Wissenschaft, 1855 (geschrieben 1848 ), S. 69.

40 Friedrich Noellner, Die deutschen Einheıtsbestrebungen im Sinne nationaler Gesetzgebung und Rechtspflege, i 857 , S. 37. Zum Programm der Germanistenversammlungen vgl. Franz Wieacker, Privatrechtsgeschichte der Neuzett, 2. Aufl. I967, S. 4 I I f.

41 Franz Wieacker a. a. O., S. 455.

42 Aus den Vorlagen von Georg Beseler, Andreas Heusler, Otto von Gierke hat Hübner eine langweilige, profillose Synthese gebildet. 
ßig ebenso ungetrübt wie von der Kenntnis der wirklichen geschichtlichen Bewegungsmechanismen, bleiben die Maßstäbe der Interpretation dem privaten Befinden des Forschers überlassen; meist werden auch diese nicht einmal expliziert.

Ebensowenig wie eine Vielzahl von Goldsuchern eine Produktiosgemeinschaft begründet, konnte der germanistische $Z$ weig der Rechtsgeschichte vom Gegenstand seiner Arbeit und dem dominanten Arbeitsinteresse eine Forschungseinheit bilden und so nennenswerte historische Entwicklungszusammenhänge bloßlegen. Der Anschluß an die Methodendiskussion und die Fragestellungen der allgemeinen Geschichtswissenschaft ${ }^{43}$ ist auch auf der tradierten juristischen Domäne der Verfassungsgeschichte verloren.

Die zivilistische Schulung, die als traditionelle Zierde der Romanistik galt (und gilt) und vielen den Absprung in das Zivil-, Arbeits- oder Wirtschaftsrecht erleichterte, wurde den Germanisten weniger großzügig attestiert; zwar galten (und gelten) die Deutschrechtler im Hinblick auf deutschrechtliche Ursprünge des Handelsrechts als Spezialisten dieses Fachs, betrachteten die Beschäftigung mit ihm jedoch seit der Wende der Germanistik zum Konservativismus Ende des 19. Jahrhunderts und der dadurch bedingten "Entfremdung « vom juristischdogmatischen Kalkül der kapitalistischen Okonomie eher als ärgerliche Nebenbeschäftigung.

Die Differenz des Gegenstandes zur romanistischen Schule erklärt auch den Unterschied, den die Deutsche Rechtsgeschichte in ihrer sozialen Funktion gegenüber der Romanistik kennzeichnet: Sie diente nicht so sehr der rationalistisch-rechtsstaatlichen Konstitution des Richterstandes, sondern teils der Legitimation der Inhalte juristischer Dogmatik als historischer, teils der konservativ-ständischen Kritik der individualisierten bürgerlichen Privatrechtsgesellschaft, die die Solidarität der Bürger, ihre ideologische Einheit bzw. "Mitte« verloren hat.

Die deutschrechtliche Kritik am Liberalismus, zusätzlich verschärft durch die oftmals bis zur persönlichen Verfeindung gehende Konkurrenz zu den »kalten «, »fremdrecht]ichen « Romanisten, ließ die germanistischen Rechtshistoriker im Gegensatz zu den Römischrechtlern politisch offen konservativ engagiert auftreten bis hin zur weitgehenden Kompromittierung im Faschismus. ${ }^{44}$

Auch heute lassen sie sich - und jetzt im Bunde mit den durch Auszehrung und die ansatzweise Politisierung universitärer Entscheidungsvorgänge aufgeschreckten Romanisten - eher den konservativen Gruppen in den juristischen Fakultäten zurechnen. Doch auch ihre Perspektiven ideologisch erfolgreicher wissenschaftlicher Forschung und Lehre sind verdüstert: Die bürgerliche Gesellschaft kann zwar auf dunkle Mythen nicht verzichten, doch holt sie sie - jedenfalls in der BRD - nicht mehr aus dem Keller der Vergangenheit, seit der Mythos des 20. Jahrhunderts die Zukunft technokratischer bzw. technizistischer Evolution geworden ist.

43 Vgl. hierzu den Aufsatz von Thomas Bark, Die Entstehung des BGB im Spiegel der bürgerlichen Rechtsgeschichte, in diesem Heft S. is $8 \mathrm{ff}$.

44 Vgl. den Beitrag von Roderich Wahsner, Die Deutsche Rechtsgeschichte und der Faschismus, in diesem Heft S. $172 \mathrm{ff}$. 


\section{DIE NOTWENDIGE UNGESCHICHTLICHKEIT DER BÜRGERLICHEN RECHTSGESCHICHTE}

\section{A. Die Verkebrung gesellschaflich-bistorischer Formen zur Naturform als Aus- druck der kapitalistischen Zirkulationsideologie}

Der Gang der bisherigen Geschichte verlief naturwüchsig, von den handelnden Individuen unbegriffen; da es ihnen auf Grund ihrer bornierten Produktionsverhältnisse nicht möglich war, den Zusammenhang ihrer Aktionen und Reaktionen

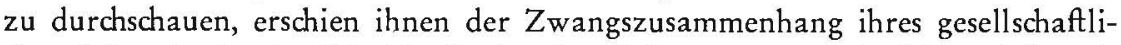
chen Seins als übersinnliche Kraft, als Idee, Geist, Gott etc., Geschichte daher als die des Schaltens eben dieser Geister, Götter, Ideen etc., Rechtsgeschichte als Geschichte der Rechtsideen und der Idee der Gerechtigkeit.

Das, was als Rechtsidee erscheint, sind die idealisierten Verhältnisse der einfachen Warenproduktion. Die Grundkategorien der bürgerlichen Gesellschaft und damit bürgerlichen Denkens sind mit dem einfachen Warenaustausch gesetzt. Die Produzenten und Eigentümer der Waren treten in gesellschaftlichen Kontakt miteinander als Repräsentanten der in ihren Waren vergegenständlichten eigenen Arbeit, die sich im Austausch als gesellschaftliche, als Wert bewährt. Im Austausch sind die Waren Aquivalente und sollen als solche gelten, sie sind und gelten als gleich. Ebenso sind die Subjekte, die diesen Austausch vollziehen, Gleiche, sie erkennen sich notwendig als Gleichgeltende und Gleichgültige an. "In der Tat, soweit die Ware oder die Arbeit nur noch als Tauschwert bestimmt ist und die Beziehung, wodurch die verschiedenen Waren aufeinander bezogen werden als Austausch dieser Tauschwerte gegeneinander, ihre Gleichsetzung, sind die Individuen, zwischen denen dieser Prozeß vorgeht, nur einfach bestimmt als Austauschende... Als Subjekte des Austauschs ist ihre Beziehung daher die der Gleichbeit. Es ist unmöglich irgendeinen Unterschied oder gar Gegensatz unter ihnen auszuspüren, nicht einmal eine Verschiedenheit. “45 Zur Bestimmung der Gleichheit der Subjekte tritt die der Freiheit und Wechselseitigkeit: „Obgleich das Individuum A Bedürfnis fühlt nach der Ware des Individuums B, bemächtigt es sich derselben nicht mit Gewalt, noch vice versa, sondern sie erkennen sich wechselseitig an als Eigentümer, als Personen, deren Willen ihre Waren durchdringt. Danach kommt hier zunächst das juristische Moment der Person herein und der Freiheit, soweit sie darin enthalten ist. Keines bemächtigt sich des Eigentums des anderen mit Gewalt. Jedes entäußert sich desselben freiwillig. Aber dies ist nicht alles: das Individuum A dient dem Bedürfnis des Individuums B vermittels der Ware a, nur insofern und weil das Individuum B dem Bedürfnis des Individuums $A$ vermittels der Ware $b$ dient und vice versa. Jedes dient dem anderen, um sich selbst zu dienen, jedes bedient sich des anderen wechselseitig als seines Mittels... Aus dem Akt des Austauschs selbst ist das Individuum, jedes derselben, in sich reflektiert als ausschließliches und herrschendes (bestimmendes) Subjekt desselben. Damit ist also die vollständige Freiheit des Individuums gesetzt: Freiwillige Transaktion; Gewalt von keiner Seite; Setzen seiner als Mittel, oder als dienend, nur als Mitte, um sich als Selbstzweck, als das Herrschende und Ubergreifende zu setzen; endlich das selbstsüchtige Interesse, kein darüberstehendes verwirklichend; der andere ist auch als ebenso sein selbstsüchtiges Interesse verwirklichend anerkannt und gewußt, so daß beide wissen, daß das ge-

45 Marx, Grundrisse der Kritik der politischen Okonomie, Ffm o. J., S. x 52 f. 
meinschaftliche Interesse eben nur in der Doppelseitigkeit, Vielseitigkeit, und Verselbständigung nach den verschiedenen Seiten, der Austausch des selbstsüchtigen Interesses ist. Das allgemeine Interesse ist eben nur die Allgemeinheit der selbstsüchtigen Interessen. Wenn also die ökonomische Form, der Austausch, nach allen Seiten hin die Gleichheit der Subjekte setzt, so der Inhalt, der Stoff, individueller sowie sachlicher, der zum Austausch treibt, die Freibeit. Gleichheit und Freiheit sind also nicht nur respektiert im Austausch, der auf Tauschwerten beruht, sondern der Austausch von Tauschwerten ist die produktive, reale Basis aller Gleichheit und Freiheit. Als reine Ideen sind sie bloß idealisierte Ausdrücke desselben, als entwickelt in juristischen, sozialen Beziehungen sind sie nur diese Basis in einer anderen Potenz. «46

Die Grundkategorien der bürgerlichen Gesellschaft, und des bürgerlichen Rechts: Eigentum, Gleichheit, Freiheit und allgemeines Gesetz sind damit in den Formen der einfachen Warenzirkulation gesellschaftlich gültige Bestimmungen. Aus der Verkehrung der Warenform zur Naturform des Arbeitsprodukts, wodurch die wertschaffende Arbeit zur scheinbar natürlichen Produktionstätigkeit wird, resultiert die Verkehrung des bürgerlichen Denkens ${ }^{47}$. Wie die Ware zum natürlichen Arbeitsprodukt, so werden ebenso sehr die sozialen Verhältnisse, die der Warenproduktion entspringen, zu natürlichen Verhältnissen und reflektieren sich im Denken als ewige, unveränderbare und wahre Bestimmungen. ${ }^{48}$ Alle anderen Verhältnisse erscheinen daher aber als falsche, unnatürliche, künstliche Verhältnisse. Diese Verhältnisse der einfachen Warenproduktion, die widerspruchsfrei gedacht werden können, werden historisch zum System der natürlichen Rechte des Menschen, zum Naturrecht. Da die naturrechtliche Theorie nicht auf die gesellschaftlichen Bedingungen ihrer Entstehung reflektiert, eben weil ihre Kategorien als natürliche und ewig sein sollende erscheinen, und weil sie historisch in der Tat als Resultat des Emanzipationskampfes des Bürgertums zum positiven Recht wird, erscheint es dieser Klasse so, als befolgten die handelnden Subjekte die Prinzipien ihres Denkens. Der Zusammenhang von gesellschaftlichem Sein und Bewußtsein verkehrt sich zur Illusion, daß die Menschen ihre Verhältnisse nach ihrem Bewußtsein einrichten.

In der Geschichtsschreibung wird dies getreulich nachgezeichnet. Allgemeine Prinzipien, Ideen regieren und große Männer richten die Geschichte danach ein. $\mathrm{Da}$ die Herkunft dieser Ideen auch von der bürgerlichen Geschichtsschreibung nicht untersucht werden kann, ${ }^{49}$ die Ideen sind ja immer schon vorhanden, er-

\footnotetext{
${ }^{46}$ Dgl., a. a. O., S. issf.
}

47 Vgl. hierzu ausführlich: H. Reichelt, Zur logischen Struktur des Kapitalbegriffs bei Karl Marx, Ffm 1970, S. 19 ff. Zum Zusammenhang von liberaler Rechtsideologie und kapitalistischer Okonomie vgl. Thomas Blanke, Funktionswandel des Streiks im Spätkapıtalismus, Ffm 1972, S. 110 ff. sowse Edkart Osborg, Zum Verhältnis von Recht und politischer Okonomie, jur. Diss. Ffm, 1973.

48 So begreift die klassısche bürgerliche Philosophie und Okonomie das bürgerliche Individuum des 18 . Jahrhunderts »nicht als ein historisches Resultat, sondern als Ausgangspunkt der Geschichte. Weil als das Naturgemäße Individuum, angemessen ihrer Vorstellung von der menschlichen Natur, nicht als ein geschichtlich entstehendes, sondern von der Natur gesetztes. Diese Täuschung 1st jeder neuen Epoche bisher eigen gewesen $\alpha$. Marx, Einleitung in die Kritik der politischen Okonomie, Grundrisse, a. a. O., S. sf.

40 "Die ganze bisherige Geschichtsauffassung hat diese wirkliche Basis der Geschichte entweder ganz und gar unberücksıchtigt gelassen oder sie nur als eine Nebensache betrachtet, die mit dem geschichtlichen Verlauf außer allem Zusammenhang steht. Die Geschschte muß daher immer nach einem außer ihr liegenden Maßstab geschrieben werden; die wirkliche Lebensproduktion erscheint als urgeschichtlich, während das Geschichtliche als das vom gemeinen Leben Getrennte, Extra-Überweltliche erscheint. Das Verhältnis der Menschen zur Natur ist hiermit von der Geschichte ausgeschlossen, wodurch der Gegensatz von Natur und Geschichte erzeugt 
scheint als Rechtsgeschichte somit der Gang der Rechtsidee und ihrer großen Denker durch die Geschichte. Jedoch stellt sich dieser Gang antinomisch dar: Als ewige Auseinandersetzung der wahren Rechtsideen (inclusive Denkern) mit der schlechten Wirklichkeit und ihren schlechten Menschen, die sich gegen die Rechtsidee spröde zeigen und "Reibungswiderstand « leisten.

Daß diese Antinomie von gesellschaftlichem Sein und idealem Sollen als ewige erscheint, ist gleichsam noch einmal »natürlich«. Die einfache Warenproduktion existierte historisch nur als Subsystem in Sklavenhalter- und Feudalgesellschaften.

Die Durchsetzung der Prinzipien, die dieser Form der Produktion entsprechen, geschieht historisch erst zu dem Zeitpunkt, in dem bereits das Kapital existiert. Damit aber ist die Zirkulation nur mehr Stadium des Kapitalkreislaufs, sie und ihre Prinzipien sind zur Ideologie geworden, zum Schein, hinter dem sich die Mehrwertabpressung in der Produktionssphäre verbirgt.

Form und Inhalt fallen damit notwendig auseinander, die gesellschaftlichen Beziehungen sind nur noch formal die der Freiheit / Gleichheit / Wechselseitigkeit. Mit dem Auftauchen der Ware Arbeitskraft auf dem Markt verkehren sich Freiheit und Gleichheit in ihr Gegenteil: "Vergangene Aneignung fremder Arbeit erscheint jetzt als einfache Bedingung für neue Aneignung fremder Arbeit. «50 Der äquivalente Austausch zwischen den Warenbesitzern schlägt mit dem Austausch zwischen Lohnarbeit und Kapital dialektisch um, so »daß auf der einen Seite nur zum Schein ausgetauscht wird, indem der gegen lebendiges Arbeitsvermögen ausgetauschte Teil des Kapitals, erstens selbst fremde Arbeit ist, angeeignet ohne Aquivalent, und zweitens mit einem Surplus vom Arbeitsvermögen ersetzt werden $m u \beta$, also in fact nicht fortgegeben wird, sondern nur aus einer Form in die andere verwandelt wird. Das Verhältnis des Austauschs ist also gänzlich weggefallen, oder ist bloßer Schein. Ferner erschien ursprünglich das Eigentumsrecht gegründet auf die eigne Arbeit. Eigentum erscheint jetzt als Recht auf fremde Arbeit und als Unmöglichkeit der Arbeit, sich ihr eignes Produkt anzueignen. Die völlige Trennung zwischen Eigentum und noch mehr Reichtum und Arbeiter scheint jetzt als Konsequenz des Gesetzes, das von ihrer Identität ausging. « ${ }^{51}$

Dem in der Zirkulationssphäre befangenen Kleinbürger und dem Bildungsbürgertum, das sich ausschließlich mit den überirdischen Sphären der reinen Ideen beschäftigt, erscheinen die notwendigen Resultate des Kapitalismus als Auswuchs, ökonomische Macht, sich vergrößernder Reichtum bei wachsender Armut erscheinen als falsche Praktizierung des an sich Richtigen, als verwerfliches Ausnutzen rechtlicher Vorteile ${ }^{52}$. Diesen notwendigen Resultaten kapitalistischer Produktion wird die reine Idee entgegengesetzt, das ewige Sollen. Diesen kleinbürgerlichen Vorstellungen, »die demonstrieren, daß der Austausch, der Tauschwert etc. ursprünglich (in der Zeit) oder ihrem Begriff nach (in ihrer adäquaten Form) ein System der Freiheit und Gleichheit aller sind, aber verfälscht worden sind durch das Geld, Kapital etc. Oder auch, daß die Geschichte bisher noch verfehlte Versuche gemacht, sie in der ihrer Wahrheit entsprechenden Weise durchzuführen, ... . ist zu antworten: Daß der 'Tauschwert oder näher das Geld-

wird. Sie hat daher in der Geschichte nur Haupt- und Staatsaktionen und religiöse und überhaupt theoretische Kämpfe sehen können und spezıell bei jeder Epoche die Illusion dieser Epoche teilen müsscn. « Marx/Engels, Die Deutsche Ideologie, MEW Bd. 3, S. 39.

50 Marx, Grundrisse, a. a. O., S. 361

51 Dgl., a. a. O., S. 362.

52 Vgl. Mittess, Vom Lebenswert der Rechtsgeschichte, S. 64. 
system in der Tat das System der Gleichheit und Freiheit ist und daß, was ihnen in der näheren Entwicklung des Systems störend entgegentritt, ihm immanente Störungen sind, eben die Verwirklichung der Gleichbeit und Freibeit, die sich ausweisen als Ungleichheit und Unfreiheit. «53

$\mathrm{Da}$ das Rad des Kapitals sich nicht zurückdrehen läßt, muß es notwendig bei dieser Antinomie bleiben: Das Sein sperrt sich dem Sollen.

\section{B. Determinanten bürgerlicher Wissenschaftsproduktion}

"Es muß diese Geschichtsmethode, die in Deutschland, und warum vornehmlich, entwickelt werden aus dem Zusammenhang mit der Illusion der Ideologen überhaupt, z. B. den Illusionen der Juristen, Politiker (auch der praktischen Staatsmänner darunter), aus den dogmatischen Träumereien und Verdrehungen dieser Kerls, die sich ganz einfach erklärt aus ihrer praktischen Lebensstellung, ihrem Geschäft und der Teilung der Arbeit. «54

Die Beschäftigung mit »reiner « Theorie, mit Wissenschaft, losgelöst von der materiellen Reproduktion der Gesellschaft wird historisch erst dann möglich, wenn gesamtgesellschaftlich genug produziert wird, um eine Schicht von Geistesarbeitern mitzuernähren. Von diesem Zeitpunkt der Trennung von geistiger und körperlicher Arbeit an »kann sich das Bewußtsein wirklich einbilden, etwas anderes als das Bewußtsein der bestehenden Praxis zu sein, wirklich etwas vorzustellen, ohne etwas Wirkliches vorzustellen - von diesem Augenblick an ist das Bewußtsein imstande, sich von der Welt zu emanzipieren und zur Bildung der » reinen * Theorie, Theologie, Philosophie, Moral etc. überzugehen. «55

Obwohl die Wissenschaft abgesetzt von der unmittelbaren Produktion in der Institution Universität einen Freiraum erhält, gelten doch die sozialen Beziehungen und Formen der bürgerlichen Gesellschaft auch in der Universität als »Wissenschaftsenklave ${ }^{56}$ Die Wissenschaftler der arbeitsteilig arbeitenden Wissenschaften tauschen ihre Resultate als Produkte ihrer eigenen Arbeit analog den Prinzipien der einfachen Warenproduktion miteinander aus. "Thre sozialen Beziehungen untereinander sind nicht gesetzt durch individuelle Kontakte oder persönliche Abhängigkeitsverhältnisse, sondern durch den Austausch ihrer Arbeiten. Sie verfügen zwar individuell über ihre eigenen Produktionsbedingungen auch wenn sie nicht juristisch Eigentümer derselben sind -, doch ihre individuelle Freiheit wird begrenzt durch das gesellschaftliche Wissen, das durch die Produktionsverhältnisse und das allgemeine Niveau der Produktivkräfte bestimmt ist. Ziele und Methoden der privat produzierenden Wissenschaftler bleiben im Rahmen des arbeitsteilig produzierten gesellschaftlichen Wissens. Die Resultate dieser Wissenschaftler sind Teile des allgemeinen Wissens und werden als solche von ihnen bestimmt; als Resultate der privat produzierenden Wissenschaftler müssen sie mit dem Ganzen des gesellschaftlichen Wissens vermittelt werden, müssen sie ausgetauscht werden, bedarf der eine Wissenschaftler der Produkte des anderen und umgekehrt; sieht er im Produkt des einen das Objekt seines Bedürfnisses, ist er auf den anderen bezogen als der Repräsentant seines Produkts und umgekehrt. Er tauscht nicht aus, weil er von dem anderen individuell abhängig ist, sondern weil er des Produkts des anderen bedarf, um seine Existenz als Wissen-

53 Marx, Grundrisse, a. a. O., S. 160.

54 Marx/Engels, Die Deutsche Ideologie, a. a. O., S. 49 f.

55 Marx/Engels, Die Deutsche Ideologie, a. a. O., S. 3 I.

5o Steffen/Funken, Die einfache Kaderproduktion, Kursbuch Nr. 2 5, 1971, S. I 29. 
schaftler reproduzieren zu können. «57 Zwar vollzieht sich die Produktion der wissenschaftlichen Ergebnisse in feudalen Formen - und dies war einer der zentralen Angriffspunkte der Studentenbewegung; untereinander verkehren sie jedoch (als "ordentliche " Professoren) als Gleiche und der Austausch ihrer Produkte vollzieht sich analog den Strukturen der einfachen Warenzirkulation in formaler und inhaltlicher Freiheit / Gleichheit / Wechselseitigkeit.

Der Rechtsgeschichtsbegriff der Rechtshistoriker speist sich somit aus zwei Quellen: Einmal aus dem Schein der Oberfläche der kapitalistischen Gesellschaft, den aus der Zirkulationssphäre stammenden formalen Rechtskategorien, die scheinbar ewigen Charakter besitzen. Zum anderen aus der sozialen Stellung der bürgerlichen Wissenschaftler, die in der Universität nach den Prinzipien der einfachen Warenproduktion untereinander verkehren. Unter kapitalistischen Verhältnissen produzieren sie damit einerseits die notwendige Ideologie, andererseits repräsentieren sie theoretisch die praktische Lage des Kleinbürgers. ${ }^{58}$

In der Krise erweist das Kapital, daß seine Rationalität nur der Schein seiner Irrationalität ist. Daher wandelt sich in diesen Situationen, in denen der Widerspruch zwischen ideellem Anspruch und kapitalistischer Wirklichkeit zu groß wird, die Gestalt der Rechtsidee: Sie sucht Zuflucht zu reaktionär-antikapitalistischen Momenten. Vom Genossenschaftsrecht bis zur Volks- und Betriebsgemeinschaft zieht sich der Reigen der durch die Geschichte legitimierten neuen Rechtsideen $^{59}$. Damit verkommt schließlich die einstige formale Rationalität bürgerlichen Denkens zur schlechten Mystik; auch insoweit erweisen sich die Rechtshistoriker, speziell der Deutschen Rechtsgeschichte, als kompetente theoretische Vertreter des Kleinbürgertums.

\section{Ideologie und Klassenlage}

Für die bürgerliche Rechtsgeschichte kann es ebensowenig einen praktischen Begriff von Geschichte geben wie für das bürgerliche Denken insgesamt. Wenn man unter Geschichte die bewußte Veränderung der Formen der Naturbeherrschung und der sich dabei herstellenden Vergesellschaftungsformen der Menschen versteht, dann muß die bürgerliche Geschichtsauffassung diesen Geschichtsbegriff notwendig verfehlen; denn die bürgerliche Klasse ist in der einmal durchgesetzten bürgerlichen Herrschaftsordnung keiner historisch emanzipativen solida-

\footnotetext{
57 Steffen/Funken, a. a. O., S. I 30.

58 „Man muß sıch ebensowenı vorstellen, daß die demokratıschen Repräsentanten nun alle shopkeepers sind oder für dieselben schwärmen. Sie können ihrer Bildung und ihrer Lage nach himmelweıt von ihnen getrennt seın. Was sie zu Vertretern des Klesnbürgertums macht, ist, daß sıe $1 \mathrm{~m}$ Kopfe nıcht über die Schranken hınauskommen, worüber jener im Leben nıcht hınauskommt, daß sıe daher zu denselben Aufgaben und Lösungen theoretısch getrieben werden, wohın jenen das materielle Interesse und die gesellschaftliche Lage praktisch treiben. Dies ist überhaupt das Verhältnıs der politischen und literarıschen Vertreter einer Klasse zu der Klasse, die sie vertreten. «arx, Der 18. Brumare des Lous Bonaparte, MEW Bd. 8, S. I 42.

59 Dementsprechend kommt in relativ krisenfreten Zeiten der Restauration kapitalistischer Verhältnisse wie der sog. Rekonstruktionsphase des westdeutschen Kapitals nach dem 2. Weltkrieg die Rechtsidee wieder in altbekannter Gestalt hervor: Als Neuauflage naturrechtlicher Ideologeme.

Insgesamt kann der Zusammenhang von Kapitalbewegung und Wandlung der Rechtsformen und -inhalte hier nur angedeutet werden. Eine genauere Untersuchung dieses Zusammenhangs müßte ausgehen von der konkreten Entwicklung des Kapıtalverhältnısses in Deutschland und dessen Veränderungen in den Phasen des Imperialismus und Faschismus, um auf dieser Folie den Wandel der rechtlichen Ausdrucksformen als notwendige Resultate dieser Entwidklung aufzuzeigen. Vgl. hierzu die Vorstudien zu einem derartigen Unternehmen bei E. Osborg, a. a. O. oben Nr. 47 .
} 
rischen Praxis mehr fähig, Geschichte kann ihr bestenfalls Reminiszenz an jenen kollektiven Kampf sein, mit dem das Bürgertum seine Klassenherrschaft errichtete. ${ }^{60}$ Und selbst diesen geschichtlichen Akt muß bürgerliches Denken noch leugnen oder verfälschen, weil es das ihm innewohnende Moment der Neuerrichtung von Klassenherrschaft verdrängen und an dessen Stelle das Trugbild einer herrschaftsfreien Gesellschaft setzen muß: "Somit hat es eine Geschichte gegeben, aber es gibt keine mehr «. ${ }^{61}$

Die Geschichtsverleugnung bürgerlichen Denkens ist nicht zufälliger Irrtum genausowenig wie bewußte Lüge. Sie ist das notwendig falsche und rechtfertigende Bewußtsein der bürgerlichen Klasse. Sie ist Ideologie $\mathrm{e}^{\mathbf{6 2}}$ und hat als solche partiellen Wahrheitsgehalt: die bürgerliche Gesellschaft erscheint geschichtslos und in Veränderung begriffen zugleich. Unter universeller Geltung der Warenform nehmen die gesellschaftlichen Beziehungen Dingcharakter an und haben so Macht über die Menschen. Ihre Bewegung ist eine Bewegung der Dinge und deshalb keine Geschichte. Die Widersprüchlichkeit der Bewegung der Dinge erzeugt eruptive undurchschaute Veränderung. Die Menschen führen diese Veränderung aus, sie beherrschen sie aber nicht. Sie sind »Charaktermasken $« .63$

In der warentauschenden Gesellschaft sind die bürgerlichen Individuen vereinzelt und dem Wertgesetz unterworfen. Ihre Praxis ist nie eine unmittelbar gesellschaftliche, sondern eine scheinbar private, die erst auf dem Markt zwangsweise in einen undurchschauten und gegenüber den Produzenten verselbständigten gesellschaftlichen Zusammenhang gestellt ist. So ergibt sich für das bürgerliche Individuum die unauflösbare Antinomie von "freier « individueller Praxis und gesellschaftlicher Untätigkeit und Ohnmacht, die sich in allen bürgerlichen Lebensäußerungen und Denkformen wiederfindet. ${ }^{64}$ Entwicklung kann in der bürgerlichen Gesellschaft nicht auf das planvolle Handeln der Menschen zurückge-

60 Hier wäre zu unterscheiden zwischen der bürgerlichen Geschichtsschreibung Deutschlands und der Englands und Frankreıchs. Das Fehlschlagen eıner wırklichen bürgerlichen Revolution in Deutschland entzweit die bürgerliche Klasse nicht nur von ihrer cıgenen Geschichte, sondern drängt ihr auch eın anderes Verhältnis zu den bürgerlichen Revolutionen auf als es die Bourgeorsie Englands und Frankreichs hat.

61 „Wenn dic Okonomen sagen, daß die gegenwärtıgen Verhältnisse - die Verhältnisse der bürgerlichen Produktıon - natürliche sınd, so geber sıe damı zu verstehen, daß es Verhältnisse sind, in denen die Erzeugung des Reichtums und die Entwicklung der Produktıvkrätte sich gemäß den Naturgesetzen vollziehen. Somıt sind diese Verhältnısse selbst von dem Einfluß der Zeıt unabhängıge Naturgesetzc. Es sind ewıge Gesetzc, welche stets die Gesellschaft zu regieren haben. Somıt hat es eine Geschichte gegeben, aber es gibt keine mehr; es hat eine Geschichte gegeben, weil feudale Einrichtungen bestanden haben und weil man in diesen feudalen Einrıchtungen Produktıonsverhältmisse findet, vollständig verscheden von denen der bürgerlichen Gesellschaft, welche die Okonomen als natürliche und demgemäß ewige angesehen wissen wollen «: K. Marx, Das Elend der Philosophie, MEW Bd. 4, S. $139 \mathrm{f}$.

02 Zum marxistischen Ideologiebegriff vgl. den yon Kurt Lenk herausgegebenen Sammelband "Ideologıc", 3. Aufl., Neuwıed und Berlin I 967, darın ınsbesondere die Einleıtung des Herausgebers und die Beıträge von Erıch Hahn und Vojin Milic; weiter Instıtut für Sozıalforschung, Sozıologische Exkurse, Frankfurt 1956, S. 162 ff.; Leo Kofler, Technologische Rationalität im Spärkapıtalismus. Frankfurt 1971; Ernest Mandel, Der Spätkapitalismus, Frankfurt I972, S. $432 \mathrm{ff}$.

63 Unter "Charaktermasken « versteht Marx dasselbe, was er im Vorwort zur ersten Auflage des Ersten Bandes des Kapıtals als "Personifikatıon ökonomsscher Kategorıen «, als »Träger von bestımmten Klassenverhältnissen und Interessen « bezeıchnet: MEW Bd. 23, 5. 16.

64 Die Zusammenhänge, auf denen große Teile dieser Darstellung beruhen, hat Georg Lukács in bis heute uneingeholter Weise entwickelt in seinem Aufsatz "Die Verdinglichung und das Bewußtseın des Proletariats in: Geschichte und Klassenbewußtseun, Berlin 1923. Obwohl Lukács' Darstellung der Rolle des Proletarıats deutlich subjektivistısch-ıdealistısche Züge trägt und damıt einen späteren Umschlag in den Objektıvısmus einer stalinıstischen Parteıtheorie bereits vorprogrammiert, ist doch seıne Herleitung der bürgerlichen Erkenntnisrestriktionen aus der Warenform nach wie vor aktuell. Zur Lukács-Debatte vgl. "Geschichte und Klassenbewußtseın heute«, Schwarze Reihe Nr. 12, Amsterdam r971; Alfred Schmidr, Geschichte und Struk- 
führt werden, der unmittelbare Zusammenhang zwischen individueller Praxis und gesellschaftlicher Veränderung wird zerrissen. Damit hört Praxis auf, „Geschichte zu machen «, Geschichte wird zum eigenmächtigen, blindwütigen Schicksal. ${ }^{\text {. }}$

Der Totalität des Warenfetischs entspricht der Geschichtsfetisch bürgerlichen Bewußtseins, der die Dialektik historischer Prozesse in die Zweiheit idealistischer und / oder naturnotwendiger Kausalität zerreißt. So spiegeln bis heute die bürgerlichen Geschichtsbilder die Antinomien wieder, die Georg Lukács anhand der klassischen Philosophie aufgezeigt hat. ${ }^{66}$ Sie rekurrieren entweder auf Individuen (was den Spielraum von optimistischen und pessimistischen Menschenbildern, von Führer- und Masseideologie einschließt) oder auf wie immer geartete "Vorgegebenheiten " (wie den Weltgeist, die Vorsehung, die Rasse, moderner den technologischen "Sachzwang " oder - sogar marxistischer Provenienz die "Strukturen «) als letzte Ursachen geschichtlicher Entwicklung. Um diesen Erklärungsprinzipien einigermaßen glaubhaft Geschichtsmächtigkeit zuschreiben zu können, sind sie zu deren fortgesetzter Mystifikation genötigt. Gesellschaftliche Praxis dagegen - als Prinzip von Geschichte, von Einheit gesellschaftlicher "Subjektivität« und "Objektivität« - fällt aus dem Rahmen dieser Geschichtsbilder heraus. Wie für die Gegenwart, so erst recht für die Vergangenheit.

In diesem Traditions- und Verblendungszusammenhang stehen die eingangs zitierten Rechtshistoriker. Auf dem Gebiet der Rechtsgeschichte tun sie, was bürgerliches Denken auf dem Gebiet der Geschichte überhaupt tut: Sie zerreißen die geschichtliche Totalität in individuelle Praxis und gesellschaftliche Ohnmacht, sie verleugnen die Ebene kollektiver Praxis und begeben sich damit der Möglichkeit rationaler Geschichtsdeutung. So entstehen die Mythen um die "großen Rechtsdenker " und genialen Persönlichkeiten einerseits, die selbstwirkende Rechtsidee und den Volksgeist andererseits. So entsteht auch das unverstandene und unverstehbare Sammelsurium von jeweiligen Rechts»zuständen ", von akribischer Quellenforschung, die doch keinen Sinn gibt.

Die Geschichte der etablierten bürgerlichen Klasse ist die der Gefährdung ihrer Herrschaft. Dies spiegelt sich in den zahllosen kulturpessimistischen Geschichtsbildern, die das Bürgertum angesichts verschärfter Klassenkämpfe hervorbringt. Es spiegelt sich weiter in kraftloser, panischer Beschwörung statischer Kategorien wie der Herrschaft des Gesetzes und in der Angst vor "Anarchie", wann immer sich gesellschaftliche Entwicklung abzeichnet. Und schließlich spiegelt sich die historische Perspektivelosigkeit bürgerlichen Denkens in dem verzweifelten Bemühen um eine historische Perspektive, die notwendig rückwärtsgewandt - als die Verwirklichung der »abendländischen Idee ", " I000jähriges Reich «, korporativ-ständisch gegliederte Gesellschaft - oder hohl und phrasenhaft - wie das neugefundene Europaideal und die "Wohlstandsgesellschaft " - ausfällt. In diesen

tur, München 1971 ; Furı Cerutt, "Hegel, Lukács, Korsch. Zum dialektischen Selbstverständnis des kritischen Marxismus in: O. Negt (Hg.), Aktualität und Folgen der Philosophie Hegels, Frankfurt 1970; Helmut Fleıscher, Marxısmus und Geschichte, Frankfurt i 969 .

65 Die bürgerliche Sprache beschreibt wirtschaftliche Vorgänge mit Vorliebe in derselben Terminologie, mit der über die Wetterlage ("Klima", "Hoch - Tief ", s Konjunkturbarometer"), über den Zustand eines Kranken ("Fieberkurve", "Schwäche", "Erholung*) oder den Verlauf eines Spiels ("Punktgewınn", "aufholen - einholen" - an der Börse -, »ın die Knie gegangen", »K. O.", "Fingerspitzengefühl ") berıchtet wird. Dieser sprachliche Ausdruck gesellschaftlich produzierter Verhältnisse ist die adäquate Äußerung von deren »Entgesellschaftung «: dem Bedürfnis, im Wirtschaftlichen doch lieber den Einbruch des Naturhaft-Zufälligen als die Möglichkeit des gesellschaftlichen Plan- und Beherrschbaren zu sehen.

66 Lukács a. a. O., unter II. und Abschnitte I, 2, s des Kapıtels III., die systematisch eher noch zu II. gehören. 
gedanklichen Ausdrücken zeigt sich am deutlichsten der Zusammenhang zwischen

der objektiven gesellschaftlichen Lage und den daraus entspringenden Erkenntnisrestriktionen, denen das bürgerliche Geschichtsdenken und damit auch das Bewußtsein bürgerlicher Rechtshistoriker ausgesetzt sind.

Umgekehrt zeigt aber dieser Zusammenhang, daß die beschriebenen Erkenntnisrestriktionen dort nicht notwendig sind, wo die objektive Möglichkeit gesellschaftsverändernder Praxis besteht. Der Fetisch Ware - und alle von ihm abgeleiteten Verdinglichungsformen - setzt Vereinzelung und kollektive Ohnmacht voraus. Die Tatsache aber, daß er selbst gesellschaftliches Produkt ist, zeigt zugleich, daß er durch gesellschaftliche Praxis gebrochen werden kann.

\section{PERSPEKTIVEN EINER MATERIALISTISCHEN RECHTSGESCHICHTE}

Das akademische Fach Rechtsgeschichte unterliegt einem fortschreitenden Bedeutungsschwund. Für angehende Juristen hat das Fach keinen nennenswerten Sozialisationswert mehr; seine apokryphen Legitimationsmuster für das geltende Recht werden angesichts des technokratischen Erfordernisses nach systemfunktionalen Steuerungs- und Konfliktlösungsmechanismen obsolet. Eine wichtige Funktion dieses Faches jedoch bleibt von dessen Niedergang unberührt, ja tritt in seiner Krise eher deutlicher hervor. In seiner überkommenen Gestalt hält es den gesamten rechtshistorischen Bereich besetzt und blockiert ihn so für eine wissenschaftliche Erforschung. Die Wissenschaft der Geschichte läßt sich aber ebensowenig dauerhaft unterdrücken wie emanzipatorische gesellschaftliche Praxis selbst. Sie ist das aufgehobene Wissen der Möglichkeiten zur Veränderung und zum Abbau von Herrschaft und der Veränderbarkeit von Klassenverhältnissen. Marx und Engels haben diese Erkenntnis am Anfang der europäischen Arbeiterbewegung auf den Begriff gebracht: "Wir kennen nur eine einzige Wissenschaft, die Wissenschaft der Geschichte ".67 Wissenschaft kann sich nur um den Preis, zur Illusion, Phantasmagorie und Ideologie zu degenerieren, von ihrem Gegenstand entfernen. Je mehr eine historische Wissenschaft die wirkliche Geschichte aus dem Blickwinkel verliert, umso mehr läuft sie Gefahr, selbst von der wirklichen Geschichte vertrieben und durch eine neue Wissenschaft ersetzt zu werden.

Der Umschlag in eine neue Rechtsgeschichte kann nur in einer radikalen Rückgewinnung ihres Gegenstandes als Bewußtsein von den historischen und aktuellen Bedingungen und Möglichkeiten kollektiver emanzipatorischer Praxis bestehen. Die Rechtsgeschichte wird als bürgerliche Wissenschaft diesen Umschlag nicht aus sich selbst leisten; vielmehr kann er nur das Resultat einer Bewegung sein, die sich des transitorischen Charakters auch der bürgerlichen Gesellschaft theoretisch wie praktisch vergewissern kann. Die zunehmende Beschäftigung mit Klassenkämpfen der Vergangenheit und Gegenwart und die tastenden Schritte zum Entwurf einer materialistischen Rechtsgeschichte an westdeutschen Universitäten - zu denen dieses Heft ein Beitrag sein will - sind Reflexe der Wiedergewinnung dieses praktischen Begriffs von Geschichte innerhalb der sozialistischen Bewegung der letzten Jahre.

67 Deutsche Ideologie, MEW Bd. 3, S. I 8. 
Erkenntnisziel einer materialistischen Geschichtsauffassung ist, die Gegenwart als geschichtliche Etappe, als in Veränderung begriffen und damit auch bewußter solidarischer Veränderung zugänglich durchschaubar zu machen. Daß sie den Lernenden den Blick auf gesellschaftliche Praxis eröffnet, macht die Geschichte zum unabdingbaren Gegenstand jeder Ausbildung. Das bürgerliche Gesellschaftsbild, das nur individuelle Praxis und gesellschaftliche Ohnmacht kennt und kennen kann, reproduziert sich in den Ausbildungsprozessen als individuelle Konsum- und / oder Karriereorientierung und politische Apathie. So wenig im bürgerlichen Denken kollektive Praxis Platz hat, so wenig kann bürgerliche Sozialisation zu solidarischem Handeln befähigen.

Demgegenüber hat eine Wissenschaft, die auf den über die bürgerliche Gesellschaft hinausweisenden Widersprüchen des Kapitalismus insistiert, die Chance, die Lern- und Erfahrungsprozesse der Arbeiterbewegung wie des politischen und ökonomischen Systems insgesamt als Ergebnis kollektiver Praxis zu analysieren und daraus die Perspektive solidarischen Handelns als historischer Notwendigkeit freizulegen. Die Gegenwart verändert ihren Aggregatzustand. Sie ist nicht mehr der festgefügte und unveränderliche Block, die "Gegebenheit «, vor der die politische Apathie resignierte. Sie löst sich auf in Prozesse, Tendenzen, Widersprüche, Bewegung, stabilisierende Unterdrückungsversuche der Kapitalseite, Positionsgewinne oder -verluste der Lohnabhängigen. Zukünftiges wird präsent: das bedeutet Geschichtlichkeit der Gegenwart. Am Erlebnis des Erfolges oder Mißerfolges kollektiver Praxis bildet sich Erfahrung aus. In dieser (unmittelbaren oder tradierten) Erfahrung wird der Zusammenhang zwischen je einzelnem Handeln und gesellschaftlicher Auswirkung deutlich. Erst dieser Zusammenhang - daß je individuelles aber solidarisches (somit gesellschaftliches) Handeln die angestrebten gesellschaftlichen Auswirkungen haben kann - entkräftet die politische Apathie und eröffnet einen praktischen Begriff von Geschichte: nämlich daß Geschichte "gemacht" wird und nicht einfach "geschieht".

An den Häuserkämpfen in Frankfurt, Hamburg, Hannover beispielsweise ließe sich verfolgen, wie politische Instanzen Forderungen unter dem Druck solidarischer und von der Öffentlichkeit weithin gebilligter Rechtsverletzungen partiell aufnehmen und in Rechtsform (Verordnungen, Auflagen, "Sozialbindungspapier «) umzusetzen versuchen. Die Geschichte des Lohnfortzahlungsgesetzes hätte zurückzugehen auf den Metallarbeiterstreik von 1956/57, der den Durchbruch zur tariflichen Absicherung erzielte, und damit den Zusammenhang von gesellschaftlicher Praxis und Gesetzgebungsprozeß zu demonstrieren. Am Verlauf und den Folgen des Zeitungsdruckerstreiks 1952 wäre aufzuzeigen, unter welchen gesellschaftlichen Kräfteverhältnissen eine restriktive »ständige Rechtsprechung " (generelles Verbot des politischen Streiks) entsteht, unter welchen Bedingungen deren Durchsetzung aber auch in Frage gestellt werden kann (Streiks anläßlich des Mißtrauensvotums gegen Brandt; Ankündigung des DGB-Vorsitzenden Vetter, notfalls Arbeiter für Mitbestimmung zu mobilisieren). An den Kämpfen der frühen Weimarer Republik wäre zu demonstrieren, unter welchen Bedingungen sich die Justiz im Bündnis mit einer korrumpierten Sozialdemokratie zum blanken Instrument der Reaktion funktionalisieren läßt, ${ }^{68}$ an der gegenwärtigen chilenischen Szene, unter welchen Bedingungen Justiz vorwärtstreibende Funktion haben kann. ${ }^{69}$ Die Beispiele sind willkürlich herausgegriffen. Sie deuten an,

$68 \mathrm{Vgl}$. hierzu Erhard Lucas, "Ausnahmezustand in den ersten Jahren der Weimarer Republik * in: Kritische Justiz 1972 , S. $16_{3} \mathrm{ff}$. und $382 \mathrm{ff}$.

69 Die Krıtısche Justız wird im nächsten Heft eınıge Beıträge hıerzu veröffentlichen. 
daß es eine materialistische Rechtsgeschichte geben kann, die die Besonderheit rechtlicher Formen und Institutionen wahrnimmt (insofern auch nicht einfach in einer Sozialgeschichte aufgeht), gleichwohl aber den Anschluß an die Widersprüche und Klassenkämpfe in der kapitalistischen Gesellschaft nicht verliert. Gegenüber der allgemeinen Sozialgeschichte ist nur der Zugriff, nicht aber der Gegenstand verschieden: Rechtspositionen werden aus dem Prozeß ihrer Entstehung durch Klassenkämpfe rekonstruiert, nicht aber - wie es die bürgerliche Rechtsgeschichte tut und tun muß - von ihm abgeschnitten.

$\mathrm{Daß}$ die Beiträge dieses Heftes den soeben formulierten Anspruch nicht einlösen, liegt selbst noch am desolaten Zustand der bürgerlichen Rechtsgeschichte. Sie beschäftigen sich mit vier wichtigen Zeitperioden der deutschen politischen und ökonomischen Geschichte: der Zeit der Bauernkriege mit den ersten bürgerlichen Bestrebungen nach einem kalkulierbaren Verkehrsrecht; dem politischen Unterliegen des Bürgertums gegenüber dem Grundadel Anfang des 19. Jahrhunderts; der schließlichen kompromißhaften Entstehung eines einheitlichen Bürgerlichen Gesetzbuches; und dem deutschen Faschismus. Die Aufsätze sind sämtlich erst Vorstufen einer materialistischen Rechtsgeschichte. Sie destruieren die idealistischen und legitimatorischen Erklärungsversuche der gegenwärtigen Rechtshistoriker vor dem Hintergrund noch unausgearbeiteter materialistischer Erklärungshypothesen und legen damit erst den Weg frei für eine materialistische Deutung der Zeitperioden (Wrobel, Bark, Wahsner). In dem Aufsatz von Stamm wird zwar das Material zur Entwicklung der Produktivkräfte, der sozialen Schichtung und der rechtlichen Entwicklung im frühen 16 . Jahrhundert zusammengetragen, jedoch nicht in der Weise miteinander vermittelt, wie es eine materialistische Rechtsgeschichte zu leisten hätte. Nichtsdestoweniger dürften die Aufsätze Impulse zur Ausführung dessen geben können, was sie selbst erst programmatisch formulieren können. 